\title{
Mechanical Pretreatment of Lignocellulosic Biomass for Methane Fermentation in Innovative Reactor with Cage Mixing System
}

\author{
Paulina Rusanowska ${ }^{1}$, Marcin Zieliński', Magda Dudek', Marcin Dębowski \\ 1 Department of Environment Engineering, University of Warmia and Mazury in Olsztyn, Warszawska 117, \\ 10-720 Olsztyn, Poland \\ *Corresponding author's e-mail: paulina.jaranowska@uwm.edu.pl
}

\begin{abstract}
Disintegration of lignocellulosic biomass for energy purposes has been extensively studied. The study aimed to investigate the influence of crushed and uncrushed lignocellulosic biomass on the biogas production in an innovative reactor. The substrate fed to the reactor was Sida hermaphrodita silage mixed with cow manure. The bioreactor had an innovative design of the mixing cage system. The mixing system of the bioreactor consisted of two cylindrical stirrers in the form of a cage. The cages simultaneously rotate around the axis of the bioreactor at against their own axes. The bioreactor is currently presented under the Record Biomap program (Horizon 2020). The bioreactor was operated at organic compounds loading of $2 \mathrm{~kg} /\left(\mathrm{m}^{3} \cdot \mathrm{d}\right)$ and $3 \mathrm{~kg} /\left(\mathrm{m}^{3} \cdot \mathrm{d}\right)$ and hydraulic retention time was $50 \mathrm{~d}$ and $33 \mathrm{~d}$, respectively. The biogas production under the organic compounds loading of $2 \mathrm{~kg} \mathrm{VS} /\left(\mathrm{m}^{3} \cdot \mathrm{d}\right)$ was $680 \mathrm{~L} / \mathrm{kg}$ VS from crushed lignocellulosic biomass and $570 \mathrm{~L} / \mathrm{kg}$ VS from uncrushed lignocellulosic biomass. The biogas production under the organic compounds loading $3 \mathrm{~kg} \mathrm{VS} /\left(\mathrm{m}^{3} \cdot \mathrm{d}\right)$ was $730 \mathrm{~L} / \mathrm{kg} \mathrm{VS}$ from crushed lignocellulosic biomass and $630 \mathrm{~L} / \mathrm{kg}$ VS from uncrushed lignocellulosic biomass. The crushing of substrate did not influence the methane content in the biogas. In all experiments, the biogas comprised about $54 \%$ of methane. The net energy efficiency was calculated as well.
\end{abstract}

Keywords: pretreatment, lignocellulose, methane production, net energy efficiency

\section{INTRODUCTION}

Nowadays, biogas plants are substrates mainly composed of lignocellulose that is included in such materials as agricultural and forestry wastes, municipal solid waste, and herbaceous energy crops [Bhatia et al. 2017]. Lignocelluloses are composed of cellulose, hemicellulose, lignin, as well as of organic and inorganic compounds. The structure of lignocellulose is such that cellulose forms a skeleton surrounded by hemicellulose and lignin, functioning as a matrix and encrusting materials. Cellulose and hemicellulose should be converted to monosaccharides in order to enhance the fermentation and biogas production. The structure of lignocellulosic biomass hinders its decomposition. The inherent properties of biomass are crystallinity of cellulose, its accessible surface area, protection by lignin and hemicellu- lose, degree of cellulose polymerization, and degree of acetylation of hemicelluloses. The carbohydrate polymers are tightly bound to the lignin, mainly by hydrogen bonds but also by some covalent bonds. Lignin is the most recalcitrant component itself, and it protects cellulose and hemicelluloses by forming tight bonds which reduce the surface area available for the enzyme attack hindering degradation of the entire carbohydrate structure. Thus, degradation of untreated lignocellulose substrates usually does not exceed $20 \%$ [Kratky and Jirout 2010]. Therefore, pretreatment is a crucial process in order to eliminate the physical and chemical barriers and improve the biodegradability of carbohydrates and lignocellulose.

Recently, the co-digestion of lignocellulose biomass with animal manure has been studied. The content of VS per volume unit of slurry manure is relatively low, thus the addition of animal 
manure to lignocellulose biomass increases the moisture of the substrate fed to anaerobic reactor [Tsapekos et al. 2017]. Co-digestion of dairy cow slurry with energy rich co-substrates has shown promising results in terms of increasing the biogas yield [Zieliński et al. 2017]. The anaerobic digestion is also relatively stable as it benefits dairy cow slurry with many positive effects. However, animal manure has also relatively high lignocellulose content. Therefore, the pretreatment of the substrate consisting of lignocellulosic biomass and animal manure is an essential step in order to increase the cellulose and hemicellulose accessibility and hydrolysis efficiency. A lot of methods have been described in the literature. The pretreatment methods are classified as physical, chemical, physiochemical and biological. The applied method changes the biomass properties in order to increase the accessibility to cellulose. Pretreatment releases sugars, but also leads to the production of other toxic byproducts (furan aldehyde, organic acid and phenolic compounds) [Allen et al. 2010]. The pretreatment method should be inexpensive, as well as characterized by low energy demand and low emission of pollution. In the biogas plant, the pretreatment usually reduces the size of biomass to enhance the heat and mass transfer during the first step of fermentation, i.e. hydrolysis. The biomass size should be reduced to $1-2 \mathrm{~mm}$. Particle size reduction increases the available surface area and reduces the cellulose crystallinity. These parameters lead to the increase of hydrolysis yield by $5-25 \%$ and reduction of digestion time by 23-59\% [Kratky and Jirout 2010, Rodrigues at al. 2017]. Although the efficiency of pretreatment has been widely confirmed through pilot or even full-scale studies, there is still conflict over the feasibility of the pretreatment from an economic point of view, due to its high energy or chemicals consumptions [Paudel et al. 2017]. Nevertheless, in order to achieve the second generation biofuel goal, it is beyond doubt that the use of a pretreatment is necessary to enhance the biogas production from agricultural residues with large content of lignocellulose.

The mechanical pretreatment is considered to be one of the most expensive processing steps in conversion of biomass to fermentable sugars. Reducing the energy requirements improves the whole process economics. Generally, the energy requirement of mechanical comminuting depends on the machine type and its variables, initial and final particle sizes, and the biomass characteristics, i.e., processing amount, composition, and mois- ture content. The right grinding solution depends especially on the moisture content in the biomass. Colloid mills and extruders are suitable only for comminuting wet materials with the moisture content over 15-20\% (wet basis), whereas hammer and especially knife mills are suitable only for comminuting the dry biomass with moisture content up to $10-15 \%$ (wet basis) [Taherzadeh and Karimi 2008]. Pretreatment methods usually consume about $33 \%$ of the total energy demand. Thus, selection of an appropriate method for pretreatment would improve the whole process economics [Kratky and Jirout 2010].

The organic loading rate has a significant influence on the stability of methane fermentation. The organic loading rate should be optimized to provide appropriate operational conditions for commercial scale reactors [Zhou et al. 2017]. Li et al. [2015] co-digested rice straw and pig manure with optimal organic loading from 3.0-12.0 $\mathrm{g} \mathrm{VS} /\left(\mathrm{dm}^{3} \cdot \mathrm{d}\right)$, and a specific biogas production of $413 \mathrm{~cm}^{3} / \mathrm{g}$ VS was achieved the organic loading rate ranging from 3 to $8 \mathrm{~g} \mathrm{VS} /\left(\mathrm{dm}^{3} \cdot \mathrm{d}\right)$. Even low changes of organic loads could affect the methane fermentation performance and stability. Thus, the aim of the present study was to investigate of mechanical pretreatment by crushing substrate on the methane fermentation of Sida hermaphrodita silage mixed with cattle manure.

\section{MATERIALS AND METHODS}

In the study, the influence of mechanical pretreatment of the substrate fed to a reactor with methane fermentation on biogas production was examined. The methane fermentation was performed in a bioreactor on fractional-technical scale. The bioreactor had an innovative design of the cage mixing system (Fig. 1). The bioreactor has a tubular tank with internal diameter of 1.2 $\mathrm{m}$ and height of $0.4 \mathrm{~m}$. The active volume of the bioreactor was $339 \mathrm{~L}$. The operating height of 0.3 $\mathrm{m}$ was filled with anaerobic sludge. Above, the gas phase was present, in which biogas was collected. In order to provide the anaerobic conditions, the reactor was closed with a dome, which the side walls were located below the liquid level in the reactor. The mixing system of the reactor consisted of two cylindrical stirrers in the form of cage with diameter of $0.35 \mathrm{~m}$. The cages simultaneously rotate around the axis of the bioreactor at against their own axes (Fig. 1). 


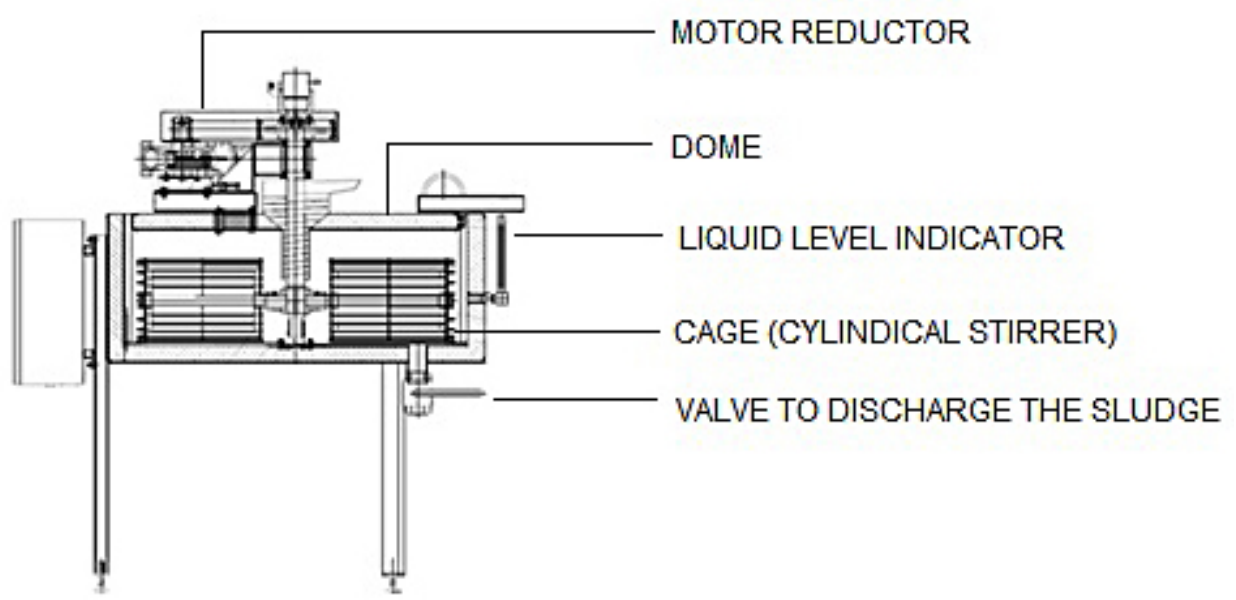

Fig. 1. Scheme of the innovative reactor with cage mixing system used in the study

The substrate used in the study was Sida hermaphrodita silage. The average value of TS in the silage was $28 \%$, volatile solids (VS) constituted $92.2 \%$ of TS and ash constituted $6.8 \%$ of TS, total nitrogen (TN) was $0.005 \mathrm{~g} / \mathrm{g}$, and COD was $1.547 \mathrm{~g} \mathrm{O} 2 / \mathrm{g}$ TS. The average value of total carbon (TC) was $0.413 \mathrm{~g} / \mathrm{g}$, and that of total organic carbon (TOC) was $0.382 \mathrm{~g} / \mathrm{g}$. In order to increase the moisture content, cow manure mixed with fresh water was added to the silage. The substrate dry mass was about $115.5 \mathrm{mg} / \mathrm{g}$, whereas it consisted of $86 \% \mathrm{VS}$.

The experiments were divided into two series. In each series the bioreactors were operated at different organic compounds loading of $2 \mathrm{~kg} /\left(\mathrm{m}^{3} \cdot \mathrm{d}\right)$ - S1 (series 1) and $3 \mathrm{~kg} /\left(\mathrm{m}^{3} \cdot \mathrm{d}\right)-\mathrm{S} 2$ (series 2). Hydraulic retention time in these bioreactors was $50 \mathrm{~d}$ and $33 \mathrm{~d}$, respectively. The studies were performed for a 100 days in each series. The analyses of substrate and digestate were conducted twice in a week. The substrate was crushed before being introduced into the bioreactor.

The mechanical pretreatment was carried out with the Börger double-pack consisting of a Multicrusher and a Rotary Lobe Pump (Börger, Germany). The twin-shaft chopper has interconnecting cutting blades. Each shaft had eight individual blades with the width of $4 \mathrm{~mm}$. The flow efficiency of the pump was $3-5 \mathrm{~m}^{3} / \mathrm{h}$.

The volume and composition of the biogas, the $\mathrm{pH}$ and the FOS/TAC ratio (explained below) were determined to monitor the anaerobic digestion process. The amount of biogas was measured with a mass flow analyzer equipped with a temporary flow rate and totalizer (Allborg). The quality of biogas was measured with an LXI 430 analyzer
(GasData) and by using a gas chromatograph connected with thermal conductivity detector (GCTCD) (Agilent 7890A). The FOS/TAC ratio was determined with TitraLab AT1000 Series Titrator (Hatch). The TAC value is an estimation of the buffer capacity of the sample, and the FOS value indicates the volatile fatty acids content. The biomass samples were tested for the content of TS and VS with a gravimetric method.

After testing for homogeneity of variance with Levene's test, the significance of differences between the variants was tested with Tukey's HSD test. Differences were considered significant at $\mathrm{p}<0.05$.

\section{RESULTS AND DISCUSSION}

In the study, the methane fermentation was investigated for different organic loading rates. When the substrate was mechanically pretreated, the daily biogas production at the organic loading rate of $2 \mathrm{~kg} /\left(\mathrm{m}^{3} \cdot \mathrm{d}\right)$ was from $318753 \mathrm{~L}$ to $496935 \mathrm{~L}$. However, in the control samples (without mechanical pretreatment) the daily biogas production at the organic loading rate of 2 $\mathrm{kg} /\left(\mathrm{m}^{3} \cdot \mathrm{d}\right)$ ranged from $198452 \mathrm{~L}$ to $391235 \mathrm{~L}$. In the samples from the reactor operated at the organic loading rate of $3 \mathrm{~kg} /\left(\mathrm{m}^{3} \cdot \mathrm{d}\right)$, mechanical pretreatment increased the daily biogas production from $336723 \mathrm{~L}$ to $576901 \mathrm{~L}$ compared to the control samples (average daily biogas production was $411119 \pm 90089 \mathrm{~L}$ ). The highest biogas production of $730 \mathrm{~L} / \mathrm{kg}$ VS was noted at organic loading rate of $3 \mathrm{~kg} /\left(\mathrm{m}^{3} \cdot \mathrm{d}\right)$. The chopping of biomass significantly increased $(p=0.005)$ the meth- 
ane fermentation in the reactors operated at both organic loading rates. In the reactor operated at the organic loading rate of $2 \mathrm{~kg} /\left(\mathrm{m}^{3} \cdot \mathrm{d}\right)$ mechanical pretreatment increased the biogas production by $8 \%$, whereas in the reactor operated at the organic loading rate of $3 \mathrm{~kg} /\left(\mathrm{m}^{3} \cdot \mathrm{d}\right)$ the enhancement of $22 \%$ was noted. Tsapekos et al. [2017] observed that mechanically pretreated grass silage increased the methane yield by $6.4 \%$ in the reactors operated at the organic loading rate of 1-1.1 $\mathrm{kg} /\left(\mathrm{m}^{3} \cdot \mathrm{d}\right)$. On the other hand, Gallegos et al. [2017] observed that reducing particle size from 2.0 to $0.2 \mathrm{~cm}$ increased the methane potential of $26 \%$. The authors performed the biomethane potential test with $450 \mathrm{~g}$ of inoculum and $2.5 \mathrm{~g}$ of volatile solids (VS) of the substrate, which resulted in the primary organics loading of $5.5 \mathrm{~kg} / \mathrm{m}^{3}$. The mechanical pretreatment probably shredded the lignocellulose to a considerable level so as to damage the intact plant's structure. However, the level of the enhancement of biogas production depends on the organic loading rate.

There were no significant differences $(p=0.05)$ in the methane content of the biogas produced. In all experiments, the methane content in biogas was about $54 \%$. On the basis of the presented results, the energy calculation of biogas was performed. Due to the high energy requirements for mechanical substrate pretreatment, the calculation of energy produced in the process and energy used for crushing was done (Table 1).

The highest energy was obtained from pretreated biomass in the reactor with the organic loading rate of $3 \mathrm{~kg} /\left(\mathrm{m}^{3} \cdot \mathrm{d}\right)$. The daily energy required for running the chopper was $75 \mathrm{Wh}$. Thus, the energy gained in both reactors operated under different organic loading rate was significantly $(p=0.05)$ higher (of about $200 \mathrm{Wh}$ ) from the pretreated than untreated biomass. By application of the mechanical pretreatment to the biogas production, a positive energy balance was gained. Addi-

Table 1. The energy production from methane fermentation in the reactors operated at the organic loading rates of 2 and $3 \mathrm{~kg} /\left(\mathrm{m}^{3} \cdot \mathrm{d}\right)$ and from pretreated/ untreated biomass

\begin{tabular}{|c|c|c|}
\hline $\begin{array}{c}\text { Organic loading } \\
\text { rate }\end{array}$ & $2 \mathrm{~kg} /\left(\mathrm{m}^{3} \cdot \mathrm{d}\right)$ & $3 \mathrm{~kg} /\left(\mathrm{m}^{3} \cdot \mathrm{d}\right)$ \\
\hline $\begin{array}{c}\text { Pretreated } \\
\text { biomass }\end{array}$ & $1683 \mathrm{Wh} / \mathrm{d}$ & $1807 \mathrm{Wh} / \mathrm{d}$ \\
\hline $\begin{array}{c}\text { Untreated } \\
\text { biomass }\end{array}$ & $1411 \mathrm{Wh} / \mathrm{d}$ & $1559 \mathrm{Wh} / \mathrm{d}$ \\
\hline
\end{tabular}

tionally, digestate after methane fermentation of chopped biomass has improved the rheological properties compared with the untreated biomass [Mbaye et al. 2014]. Moreover, mechanical pretreatment helps to avoid the clogging problems. Therefore, comparing with screw feeder commonly used in biogas plants, chopping seems to be an attractive alternative.

As expected, the higher content of VS in digestate was observed at higher organic loading rate. After fermentation under the organic loading rate of $2 \mathrm{~kg} /\left(\mathrm{m}^{3} \cdot \mathrm{d}\right)$, volatile solids accounted of $58 \%$ TS from crushed substrate and $62 \%$ TS from uncrushed substrate. The methane fermentation under $3 \mathrm{~kg} /\left(\mathrm{m}^{3} \cdot \mathrm{d}\right)$ decreased the degradation of substrate. The content of volatile solids in digestate was $72 \%$ and $77 \%$ TS from crushed and uncrushed substrate, respectively. Significantly higher $(p=0,05)$ biomass decomposition was noted in the reactors operated under the organic loading rate of $2 \mathrm{~kg} /\left(\mathrm{m}^{3} \cdot \mathrm{d}\right)$ then in the reactors operated the under organic loading rate of $3 \mathrm{~kg} /\left(\mathrm{m}^{3} \cdot \mathrm{d}\right)$ (Fig. 2). The degradation values of $50-55 \%$ were also noted from cattle manure and food waste by Morken et al. [2018]. Higher values of degradation at the organic loading rate of $2 \mathrm{~kg} /\left(\mathrm{m}^{3} \cdot \mathrm{d}\right)$ indicated that the organic loads could be increased. The same conclusion resulted from the FOS/TAC ratio analysis; however, the FOS/TAC ratio and $\mathrm{pH}$ in all experimental reactors indicated stable process performance. The FOS/TAC ratio in digestate from the reactors operated under organic loading rate of $2 \mathrm{~kg} /\left(\mathrm{m}^{3} \cdot \mathrm{d}\right)$ was 0.166 and 0.182 from crushed and uncrushed substrate, respectively. The FOS/TAC ratio in the digestate from the reactors operated under the organic loading rate of $3 \mathrm{~kg} /\left(\mathrm{m}^{3} \cdot \mathrm{d}\right)$ slightly increased to 0.192 and 0.240 from crushed and uncrushed substrate, respectively. The $\mathrm{pH}$ was from $7.6 \pm 0.04$ (in the reactors operated under the organic loading rate of $3 \mathrm{~kg} /\left(\mathrm{m}^{3} \cdot \mathrm{d}\right)$ ) to $7.9 \pm 0.06$ (in the reactors operated under the organic loading rate of $\left.2 \mathrm{~kg} /\left(\mathrm{m}^{3} \cdot \mathrm{d}\right)\right)$.

\section{CONCLUSIONS}

Efficient methane fermentation was obtained from mechanically pretreated substrate consisting of Sida hermaphrodita silage and cattle manure. Significantly higher $(p=0.05)$ biogas production of $22 \%$ and biomass decomposition of $6 \%$ was noted from crushed substrate than from uncrushed substrate at the organic loading rate 


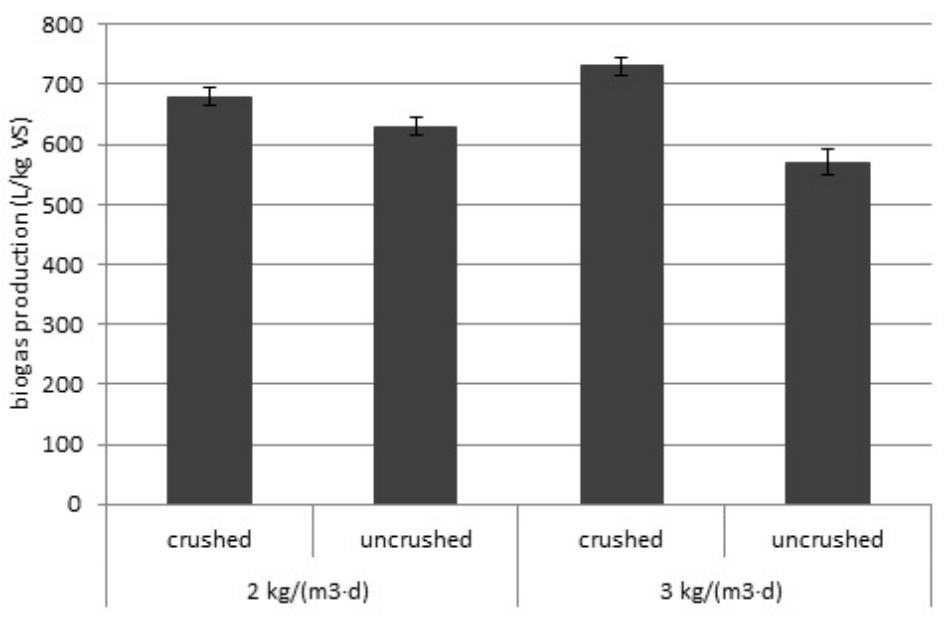

Fig. 2. The biogas production in the reactors operated at organic loading rate of 2 and $3 \mathrm{~kg} /\left(\mathrm{m}^{3} \cdot \mathrm{d}\right)$ from crushed and uncrushed substrate

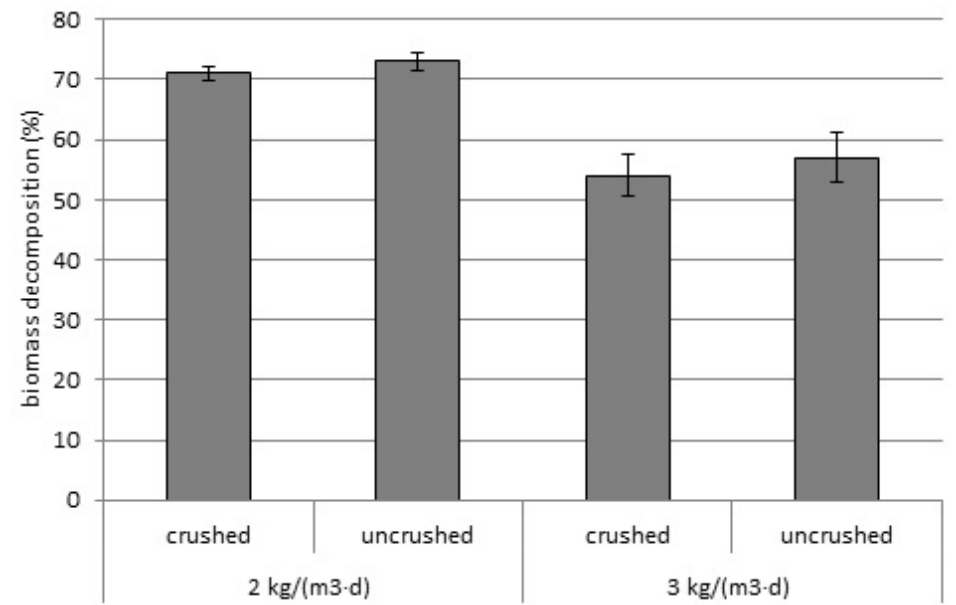

Fig. 3. Decomposition of biomass at organic loading rate of 2 and $3 \mathrm{~kg} /\left(\mathrm{m}^{3} \cdot \mathrm{d}\right)$ from crushed and uncrushed substrate

of $3 \mathrm{~kg} /\left(\mathrm{m}^{3} \cdot \mathrm{d}\right)$. By using a chopper for mechanical pretreatment, a positive energy gain was observed. Due to additional reduction of technical processing problems with mechanically pretreated biomass, crushing is a reasonable method enhancing the biogas production.

\section{Acknowledgements}

The study was carried out in the framework of the project under program BIOSTRATEG funded by the National Centre for Research and Development No. 1/270745/2/NCBR/2015 "Dietary, power, and economic potential of Sida hermaphrodita cultivation on fallow land".

The bioreactor is promoted under the project Research Coordination for a Low-Cost Biomethane Production at Small and Medium Scale
Applications (Record Biomap) Horizon 2020 research and innovation programme (Grant Agreement 691911).

This work was supported the statutory project 18.610.008-300, University of Warmia and Mazury in Olsztyn, Poland.

\section{REFERENCES}

1. Allen S.A., Clark W., McCaffery J.M., Cai Z., Lanctot A., Slininger P.J. et al. 2010. Furfural induces reactive oxygen species accumulation and cellular damage in Saccharomyces cerevisae. Biotechnology for Biofuels, 3, 1-10.

2. Bhatia S.K., Kim S.-H., Yoon J.-J., Yang Y.-H. 2017. Current status and strategies for second generation biofuel production using microbial systems. Energy Conversion and Management, 148, 1142-1156. 
3. Gallegos D., Wedwitschk H., Moeller L., Zehnsdorf A., Stinner W. 2017. Effects of particle size reduction and ensiling fermentation on biogas formation and silage quality of wheat straw. Bioresource Technology, 245, 216-224.

4. Kratky L., Jirout T. 2010. Biomass Size Reduction Machines for Enhancing Biogas Production. Chemical Engineering \& Technology, 34(3), 391-399.

5. Li D., Liu S.C., Mi L., Li Z.D., Yuan Y.X., Yan Z.Y. Liu X.F. 2015. Effects of feedstock ratio and organic loading rate on the anaerobic mesophile co-digestion of rice straw and pig manure. Bioresource Technology, 187, 120-127.

6. Mbaye S., Dieudé-Fauvel E., Baudez J.C. 2014. Comparative analysis of anaerobically digested wastes flow properties. Waste Management, 34(11), 2057-2062.

7. Morken J., Gjetmundsen M., Fjørtoft K. 2018. Determination of kinetic constants from the co-digestion of dairy cow slurry and municipal food waste at increasing organic loading rates. Renewable Energy, 117, 46-51.

8. Paudel S.R., Banjara S.P., Choi O.K., Park K.Y., Kim Y.M., Lee J.W. 2017. Pretreatment of agricultural biomass for anaerobic digestion: Current state and chal- lenges. Bioresource Technology, 245, 1194-1205.

9. Rodriguez C., Alaswad A., Benyounis K.Y., Olabi A.G. 2017. Pretreatment techniques used in biogas production from grass. Renewable and Sustainable Energy Reviews, 68, 1193-1204.

10. Taherzadeh M.J., Karimi K. 2008. Pretreatment of Lignocellulosic Wastes to Improve Ethanol and Biogas Production: A Review. International Journal of Molecular Sciences, 9(9), 1621-51.

11. Tsapekos P., Kougias P.G., Treu L., Campanaro S., Angelidaki I. 2017. Process performance and comparative metagenomic analysis during co-digestion of manure and lignocellulosic biomass for biogas production. Applied Energy, 185, 126-135.

12. Zieliński M., Dębowski M., Kisielewska M., Nowicka A., Rokicka M., Szwarc K. 2017. Comparison of ultrasonic and hydrothermal cavitation pretreatments of cattle manure mixed with straw wheat on fermentative biogas production. Waste and Biomass Valorization. DOI: 10.1007/ s12649-017-9977-y.

13. Zhou J., Yang J., You Q., Yong X., Xie X., Zhang L., Wei P., Jia H. 2017. Different organic loading rates on the biogas production during the anaerobic digestion of rice straw. A pilot study. Bioresource Technology, 244, 865-871. 